\title{
FINANCIAL FEASIBILITY ANALYSIS OF VOERSERI BUSINESS (Packaging Bird Feed from Kersen/Singapore Cherry)
}

\section{ANALISIS KELAYAKAN FINANSIAL USAHA VOERSERI (Pakan Burung Kemasan dari Buah Kersen/Seri)}

\author{
Ridho Affandi ${ }^{1}$, Muhammad Reza Siregar ${ }^{1}$, Dini Indira Sari ${ }^{1}$, \\ Nadila Savira ${ }^{1}$, Syuhada Wulantiya ${ }^{1}$, Akbar Habib $^{2}$ \\ Program Studi Agribisnis Fakultas Pertanian Universitas Muhammadiyah Sumatera Utara \\ ${ }^{1}$ Mahasiswa Fakultas Pertanian UMSU \\ ${ }^{2}$ Dosen Fakultas Pertanian UMSU \\ Email : voers098@gmail.com
}

\begin{abstract}
Voerseri is a packaged bird feed made from singapore cherry. Voerseri is one of the developing businesses in the city of Medan. The financial feasibility analysis of the voerseri business is carried out to help the Voerseri Business see the feasibility of the development business that will be carried out. Some of the things studied in the financial feasibility analysis include variable costs, fixed costs, and business feasibility criteria which include Break Even Point (BEP), $R / C$ ratio and $B / C$ ratio. The result of the calculation of the financial viability of the Voerseri Business is that it will reach BEP by selling 79 units of products or Rp. 1,330,258 every month. The $R$ / $C$ value obtained is equal to 1.44, which means that this business is feasible to be cultivated while the B / C value obtained is equal to 0.44 , which means that this business does not provide benefits to businessmen.
\end{abstract}

Keyword: Voerseri, feasibility, business, Financial

\section{Abstrak}

Voerseri merupakan pakan burung kemasan yang terbuat dari buah kersen/seri. Voerseri merupakan salah satu usaha yang sedang berkembang di kota Medan. Analisis kelayakan finansial usaha voerseri dilakukan untuk membantu Usaha Voerseri melihat kelayakan usaha pengembangan yang akan dijalankan. Beberapa hal yang dikaji dalam analisis kelayakan finansial antara lain biaya variabel, biaya tetap, dan kriteria kelayakan usaha yang meliputi Break Even Point (BEP), R/C rasio serta B/C rasio. Hasil perhitungan kelayakan finansial Usaha Voerseri adalah akan mencapai BEP dengan menjual produk sebanyak 79 unit atau senilai $R p$. 1.330.258 setiap bulannya. Nilai $R / C$ rasio yang didapat yaitu sebesar 1,44 yang berarti usaha ini layak untuk diusahakan sedangkan nilai B/C yang didapat yaitu sebesar 0,44 yang berarti usaha ini kurang memberikan manfaat kepada pelaku usaha.

Kata Kunci: Voerseri, Kelayakan, Bisnis, Finansial

\section{A. PENDAhuluan}

Presiden jokowi dalam gelaran presiden cup tahun 2018 menyatakan bahwa perputaran uang yang dihasilkan dalam bisnis burung kicau ini mencapai 1,7 triliun Rupiah per tahun. Perputaran kicau sampai 1,7 triliun Rupiah pertahun mengindikasikan bahwa geliat usaha dan minat masyarakat terhadap burung-burung kicau semakin tahun semakin meningkat. Aktivitas-aktivitas itu mencakup pertama dari jual beli burung, kedua perternakan burung, ketiga jual beli pakan, keempat usaha-usaha kerajinan kandang dan lainnya.

Oleh karena banyaknya usaha-usaha burung kicau diikuti banyaknya kompetisi- kompetisi atau kontes perlombaan burung menyebabkan atau memacu para penggemar untuk bisa melakukan perawatan-perawatan ekstra terhadap burung kicaunya. Akhirnya penggunaan ekstra fooding itu digunakan atau racikan-racikan lain digunakan untuk memacu kinerja atau performa burung kicaunya.

Untuk itu voerseri hadir sebagai juga sebagai pakan utama sekaligus pakan alternative pendukung performa burng kususnya burung pemakan pisang karena habitat di alam liar burung pemakan pisang itu juga memakan beberapa jenis buahbuahan yang tersedia maka kita anggap burung tersebut bisa naik performanya ketika 
menggunakan pakan-pakan alami yang kita racik.

Voerseri merupakan voer atau pakan utama yang berbahan dasar buah kersen . Buah kersen di alam liar tersedia bebas dan tidak dimanfaatkan oleh masyarakat/manusia tapi sebaliknya sangat digemari oleh burungburung kicau seperti burung trucukan, cucak hijau atau cucok ijo, kemudian jenis burung cucakan-cucakan lain. Ini yang membuat voerseri kita yakin dapat diterima oleh masyarakat baik karena harganya bisa lebih murah, bahan dasarnya kita peroleh secara gratis, dan juga nanti untuk burung-burung pemakan buah diharapkan menemukan performa terbaiknya ketika sudah mengkonsumsi voerseri ini.

Penelitian ini bertujuan untuk menganalisis kelayakan finansial usaha voerseri di Kota Medan.

\section{B. METODE PENELITIAN}

Data diolah dalam bentuk tabulasi kemudian dianalisis secara matematis dengan merujuk pada aspek-aspek perhitungan analisis kelayakan finansial, yaitu Break Event Point (BEP), rasio $\mathrm{R} / \mathrm{C}$, dan rasio B/C. Data biaya variabel dan biaya tetap digunakan untuk mengetahui total biaya produksi atau total cost dengan perhitungan :

$$
\mathrm{TC}=\mathrm{TVC}+\mathrm{TFC}
$$

\section{Dimana:}

$\mathrm{TC}=$ Total $\operatorname{cost}($ Total Biaya $)$

TVC $=$ Total Variable Cost $($ Total Biaya Variabel)

TFC $=$ Total Fix Cost $($ Total Biaya Tetap)

Perhitungan harga pokok produk dilakukan untuk penetapan harga jual dengan terlebih dahulu menetapkan jumlah pruksi yang akan dilakukan dalam sebulan serta biaya variabel yang dikeluarkan per produk dapat dilihat dengan perhitungan:

$$
\begin{aligned}
& \mathrm{HPP}=\frac{\mathrm{TC}}{\mathrm{Q}} \\
& \mathrm{AVC}=\frac{T V C}{Q}
\end{aligned}
$$

Dimana:

HPP = Harga Pokok Produksi

$\mathrm{TC}=$ Total cost (Total Biaya)

$\mathrm{Q}=$ Quantity (Jumlah Produksi)

AVC $=$ Avarage Variable Cost (Biaya

Variabel per unit)
$\mathrm{TVC}=$ Total Variable Cost $($ Total Biaya Variabel)

Perhitungan penerimaan atau revenue, serta perhitungan pendapatan atau benefit melalui persamaan:

$$
\begin{aligned}
& \mathrm{TR}=\mathrm{P} \times \mathrm{Q} \\
& \mathrm{B}=\mathrm{TR}-\mathrm{TC}
\end{aligned}
$$

Dimana:

$\mathrm{TR}=$ Total Revenue $($ Total Penerimaan $)$

$\mathrm{P}=$ Price (Harga Jual per Unit)

$\mathrm{Q}=$ Quantity (Jumlah Produksi)

$\mathrm{B}=$ Benefit (Pendapatan)

$\mathrm{TC}=$ Total $\operatorname{cost}($ Total Biaya $)$

Analisis kelayakan digunakan untuk mengidentifikasi masalah di masa yang akan datang, sehingga dapat meminimalkan kemungkinan melesetnya hasil yang ingin dicapai dalam suatu investasi. Dengan kata lain, analisis kelayakan akan menghitung halhal yang akan menghambat atau peluang dari investasi yang akan dijalankan. ${ }^{1}$

Analisis kelayakan finansial menggunakan perhitungan:

BEP adalah suatu titik jumlah produksi atau penjualan yang harus dilakukan agar biaya yang dikeluarkan dapat tertutupi kembali atau nilai dimana profit yang diterima UKM adalah nol. ${ }^{2}$

$$
\text { BEP unit }=\frac{T F C}{P-A V C}
$$

atau

$$
\text { BEP rupiah }=\frac{T F C}{1-A V C / P}
$$

Dimana:

TFC = Total Fix Cost (Total Biaya Tetap)

$\mathrm{P}=$ Price (Harga Jual per Unit)

TFC = Total Fix Cost (Total Biaya Tetap)

Perhitungan $\mathrm{R} / \mathrm{C}$ rasio merupakan perbandingan antara penerimaan total dan biaya total, yang menunjukkan nilai penerimaan yang diperoleh dari setiap rupiah yang dikeluarkan.

$$
\mathrm{R} / \mathrm{C} \text { Rasio }=\frac{T R}{T C}
$$

Dimana:

$\mathrm{TR}=$ Total Revenue $($ Total Penerimaan $)$ 
$\mathrm{TC}=$ Total $\operatorname{cost}($ Total Biaya $)$

Perhitungan $\mathrm{B} / \mathrm{C}$ rasio merupakan perbandingan antara pendapatan dan biaya total, yang menunjukkan nilai pendapatan yang diperoleh dari setiap rupiah yang dikeluarkan.

$$
\mathrm{B} / \mathrm{C} \text { Rasio }=\frac{B}{T C}
$$

Dimana:

$\mathrm{B}=$ Benefit (Pendapatan)

$\mathrm{TC}=$ Total $\operatorname{cost}($ Total Biaya $)$

\section{HASIL DAN PEMBAHASAN}

Didalam usaha voerseri ini diperlukan berbagai biaya yang akan dikeluarkan dalam usaha Voerseri untuk menghasilkan 300 bungkus produk/bulan dengan harga jual sebesar Rp. 17.000,/bungkus. Adapun biaya yang akan dikeluarkan terdiri dari biaya tetap dan juga biaya variabel. Adapun biaya tetap yang digunakan dalam usaha Voerseri sebagai berikut :

Tabel 1. Biaya Penyusutan Peralatan

\begin{tabular}{llccrrrrr}
\hline No. & \multicolumn{1}{c}{ Biaya } & \multicolumn{2}{c}{ Jumlah Satuan $\begin{array}{c}\text { Harga per } \\
\text { Satuan }\end{array}$} & \multicolumn{1}{c}{$\begin{array}{c}\text { Total } \\
\text { Harga }\end{array}$} & Nilai Sisa & $\begin{array}{c}\text { Umur } \\
\text { Ekonomis }\end{array}$ & Penyusutan \\
\hline 1 & Pencetak Pelet & 1 & unit & 300.000 & 300.000 & 30.000 & 6 & 3.750 \\
2 & Baskom Stainless & 3 & unit & 40.000 & 120.000 & 12.000 & 3 & 3.000 \\
3 & Timbangan Besar & 1 & unit & 175.000 & 175.000 & 17.500 & 10 & 1.313 \\
4 & Belender & 1 & unit & 285.000 & 285.000 & 28.500 & 5 & 4.275 \\
5 & Tampah Plastik & 5 & unit & 10.000 & 50.000 & 5.000 & 2 & 1.875 \\
6 & Pisau Cutter & 2 & unit & 1.500 & 3.000 & 300 & 1 & 225 \\
7 & Sealer & 1 & unit & 165.000 & 165.000 & 16.500 & 10 & 1.238 \\
\hline \multicolumn{7}{r}{ Total } & \multicolumn{7}{c}{1.098 .000} \\
\hline
\end{tabular}

Selain biaya penyusutan yang tertera diatas terdapat biaya lain yang harus dikeluarkan pada biaya tetap ini seperti sewa gedung Rp. 500.000,-/bulan dan kuota internet Rp. 35.000,-/bulan. Sehingga didapat biaya tetap yaitu sebesar Rp. 550.675,-/bulan.

Selain biaya tetap diatas terdapat juga biaya variabel yang harus dikeluarkan dalam usaha Voerseri sebagai berikut:

Tabel 2. Biaya Bahan Baku

\begin{tabular}{clccrr}
\hline No. & Biaya & Jumlah & Satuan & Harga/Satuan & \multicolumn{1}{c}{ Total Harga } \\
\hline 1. & Tepung Tapioka & 37 & $\mathrm{Kg}$ & 10.000 & 370.000 \\
2. & Tepung Jagung & 15 & $\mathrm{Kg}$ & 9.000 & 135.000 \\
3. & Udang Kecepe & 11 & $\mathrm{Kg}$ & 32.000 & 352.000 \\
4. & Seri & 30 & $\mathrm{Kg}$ & 5.000 & 150.000 \\
5. & Daging Sapi & 4,3 & $\mathrm{Kg}$ & 120.000 & 516.000 \\
6. & Ikan lele & 2,2 & $\mathrm{Kg}$ & 50.000 & 110.000 \\
7. & Telur & 429 & $\mathrm{Butir}$ & 1.200 & 514.800 \\
8. & Pewarna & 7 & $\mathrm{Blok}$ & 2.000 & 14.000 \\
9. & Kacang Tanah & 6 & $\mathrm{Kg}$ & 20.000 & 120.000 \\
10. & Kacang Kedelai & 6 & $\mathrm{Kg}$ & 7.500 & 45.000 \\
11. & Asam amino & 6 & $\mathrm{Butir}$ & 1.000 & 6.000 \\
\hline & & & &
\end{tabular}

Tabel 3. Biaya Penunjang

\begin{tabular}{clccrr}
\hline No. & \multicolumn{1}{c}{ Biaya } & Jumlah & Satuan & Harga/Bungkus & \multicolumn{1}{c}{ Total Harga } \\
\hline 1. & Silica Gel & 300 & Bungkus & 200 & 60.000 \\
2. & Plastik Standing Pouch & 300 & Bungkus & 270 & 81.000 \\
3. & Bungkus & 300 & Unit & 2.000 & 600.000 \\
4. & Listrik/Air & & & Total & 841.000 \\
\hline
\end{tabular}


Dari tabel 2 dan tabel 3 diatas dapat kita ketahui bahwa jumlah biaya variabel pada usaha Voerseri sebanyak Rp. 2.988.800,-/bulan yang terdiri dari biaya bahan baku sebesar Rp. 2.147.800,-/bulan serta biaya penunjang sebesar Rp. 841.000,/bulan.

Adapun total biaya yang dikeluarkan usaha voerseri ini dalam sebulan yaitu sebesar:

$$
\begin{aligned}
\mathrm{TC} & =\mathrm{TFC}+\mathrm{TVC} \\
& =550.675+2.988 .800 \\
& =3.539 .475
\end{aligned}
$$

Sehingga didapat total biaya yang dikeluarkan usaha voerseri ini dalam sebulan produksi yaitu sebesar Rp. 3.539.475,-/bulan.

Adapun harga pokok produk dari produk voerseri ini yaitu sebesar:

$$
\begin{aligned}
\mathrm{HPP} & =\frac{\mathrm{TC}}{\mathrm{Q}} \\
& =\frac{3.539 .475}{300} \\
& =11.798,3
\end{aligned}
$$

Sehingga didapat harga pokok produk voerseri ini yaitu sebesar Rp. 11.798,3/bungkus.

Adapun biaya variabel yang dikeluarkan per produk yaitu sebesar:

$$
\begin{aligned}
\mathrm{AVC} & =\frac{T V C}{Q} \\
& =\frac{2.988 .800}{300} \\
& =9.962,7
\end{aligned}
$$

Sehingga didapat biaya variabel per produk voerseri ini yaitu sebesar Rp. 9.962,7/bungkus.

Adapun total penerimaan yang didapatkan usaha voerseri ini dalam sebulan yaitu sebesar:

$$
\begin{aligned}
\mathrm{TR} & =\mathrm{P} \times \mathrm{Q} \\
& =17.000 * 300 \\
& =5.100 .000
\end{aligned}
$$

Sehingga didapat total penerimaan yang didapatkan usaha voerseri ini dalam sebulan produksi yaitu sebesar Rp. 5.100.000,-/bulan.

Adapun total pendapatan bersih yang didapatkan usaha voerseri ini dalam sebulan yaitu sebesar:

$$
\begin{aligned}
\mathrm{B} & =\mathrm{TR}-\mathrm{TC} \\
& =5.100 .000-3.539 .475 \\
& =1.560 .525
\end{aligned}
$$

Sehingga dapat diketahui pendapatan bersih yang didapatkan usaha voerseri ini dalam sebulan produksi yaitu sebesar Rp. $1.560 .525,-/$ bulan.

Tabel 4. Rekapitulasi VC, FC, TC, dan penentuan HPP

\begin{tabular}{lcc}
\hline \multicolumn{1}{c}{ Uraian } & Satuan & Jumlah \\
\hline Kapasitas Produksi & Bks & 300 \\
Total FC & Rp/Bln & 550.675 \\
Total VC & Rp/Bln & 2.988 .800 \\
Total Cost & Rp/Bln & 3.539 .475 \\
Biaya Variabel per Unit & Rp/Bks & $9.962,7$ \\
HPP & Rp/Bks & $11.798,3$ \\
Harga Jual & Rp/Bks & 17.000 \\
Margin & $\%$ & 30,6 \\
Penerimaan & Rp/Bln & 5.100 .000 \\
Pendapatan & Rp/Bln & 1.560 .525 \\
\hline
\end{tabular}

Analisis Kelayakan Usaha Voerseri. Penentuan Break Event Point (BEP), R/C rasio, dan $\mathrm{B} / \mathrm{C}$ rasio digunakan untuk mengetahui kelayakan suatu usaha agroindustri dilihat dari aspek kelayakan finansial.

\section{Break Event Point (BEP)}

BEP dapat diartikan suatu keadaan dimana dalam operasi perusahaan, perusahaan tidak memperoleh laba dan tidak menderita rugi (penghasilan yang dinilai menggunakan total biaya). Adapun nilai BEP dari usaha voerseri ini yaitu:

$$
\begin{aligned}
\text { BEP unit } & =\frac{F C}{P-A V C} \\
& =\frac{550.675}{17.000-9.962,7} \\
& =78,25 \text { unit }
\end{aligned}
$$

Dari hasil yang didapatkan nilai BEP unit yang didapat yaitu sebesar 78,25 unit 
maka dikatakan titik balik modal penjualan berada pada penjualan 79 unit.

$$
\begin{aligned}
\mathrm{BEP} \text { rupiah } & =\frac{F C}{1-{ }^{A V C} / P} \\
& =\frac{550.675}{1-{ }^{9962,67 / 17.000}} \\
& =1.330 .258
\end{aligned}
$$

BEP rupiah digunakan untuk mengetahui titik balik impas modal dilihat dari penerimaannya. Dari proyek ini diketahui bahwa titik balik modal penjualan berada pada penerimaan Rp. 1.330.258,-

\section{$\mathrm{R} / \mathrm{C}$ rasio}

$$
\begin{aligned}
\mathrm{R} / \mathrm{C} \text { rasio } & =\frac{T R}{T C} \\
& =\frac{5.100 .000}{3.539 .475} \\
& =1,44
\end{aligned}
$$

Nilai rasio R/C lebih besar dari 1 maka proyek dikatakan layak secara ekonomi. Kemudian nilai rasio $\mathrm{R} / \mathrm{C}$ sama dengan 1 maka dikatakan usaha dikatakan impas secara ekonomi serta apabila nilai $\mathrm{R} / \mathrm{C}$ lebih kecil dari satu maka dikatakan proyek kurang layak secara ekonomi. Dalam proyek ini didapatkan nilai R/C sebesar 1,44 maka dikatakan usaha layak secara ekonomi bagi pelaku usaha.

\section{$\mathrm{B} / \mathrm{C}$ rasio}

$\mathrm{B} / \mathrm{C}$ rasio $=\frac{B}{T C}$

$$
\begin{aligned}
& =\frac{1.560 .525}{3.539 .475} \\
& =0,44
\end{aligned}
$$

Nilai rasio B/C lebih besar dari 1 maka proyek dikatakan memiliki manfaat bagi pelaku usaha. Kemudian nilai rasio B/C sama dengan 1 maka dikatakan usaha cukup memberikan manfaat bagi pelaku usaha serta apabila nilai B/C kurang dari 1 maka proyek dikatakan kurang memberikan manfaat terhadap pelaku usaha. Dalam proyek ini didapatkan nilai B/C sebesar 0,44 maka dikatakan usaha kurang memberikan manfaat bagi pelaku usaha.

\section{KESIMPULAN}

Kesimpulan yang didapatkan dari penelitian ini yaitu didapatkan nilai BEP unit sebesar 79 unit. Nilai BEP rupiah yang didapat yaitu pada titik penerimaan Rp. 1.330.258. Kemudian rasio $\mathrm{R} / \mathrm{C}$ yang didapatkan yaitu sebesar 1,44 yang dikatakan usaha layak secara ekonomi kemudian dari $\mathrm{B} / \mathrm{C}$ sebesar 0,44 yang dikatakan bahwa usaha kurang memberikan manfaat bagi pelaku usaha.

\section{Daftar Pustaka}

1. Kasmir dan Jakfar. 2010. Studi Kelayakan Bisnis. Edisi Revisi. K E N C A N A.

2. Pujawan, I Nyoman. 2004. Ekonomi Teknik Edisi Pertama, cetakan ketiga. Unit Penerbit dan percetakan AMP YKPN, Yogyakarta. 